\title{
Imidazolidin-4-one peptidomimetic derivatives of primaquine: Synthesis and antimalarial activity
}

\author{
Nuno Vale ${ }^{\mathrm{a}}$, Joana Matos ${ }^{\mathrm{a}}$, Jiri Gut ${ }^{\mathrm{b}}$, Fátima Nogueira ${ }^{\mathrm{c}}$, Virgílio do Rosário ${ }^{\mathrm{c}}$, Philip J. Rosenthal ${ }^{\mathrm{b}}$, \\ Rui Moreira ${ }^{\mathrm{d}}$, Paula Gomes ${ }^{\mathrm{a}, *}$
}

${ }^{a}$ CIQUP, Departamento de Química, Faculdade de Ciências, Universidade do Porto, P-4169-007 Porto, Portugal

${ }^{\mathrm{b}}$ Department of Medicine, San Francisco General Hospital, University of California, San Francisco, CA 94143-0811, USA

${ }^{\mathrm{C}}$ CMDT, Instituto de Higiene e Medicina Tropical, P-1349-008 Lisboa, Portugal

diMed.UL, CECF, Faculdade de Farmácia de Lisboa, P-1600-083 Lisboa, Portugal

\section{A R T I C L E I N F O}

\section{Article history:}

Received 5 May 2008

Revised 16 May 2008

Accepted 20 May 2008

Available online 23 May 2008

\section{Keywords:}

Antimalarial

Gametocytocidal

Imidazolidin-4-one

Malaria

Peptidomimetic

Primaquine

\begin{abstract}
A B S T R A C T
The synthesis of imidazolidin-4-one derivatives of primaquine containing the five-membered ring at the C-terminus of a dipeptide backbone coupled to the parent drug is described. These peptidomimetic derivatives were active against a chloroquine-resistant Plasmodium falciparum strain and inhibited the development of the sporogonic cycle of Plasmodium berghei, affecting the appearance of oocysts in the midguts of the mosquitoes. The novel imidazolidin-4-ones are extremely stable, both in human plasma and in $\mathrm{pH} 7.4$ buffer, as a result of $\mathrm{N}^{1}$-acylation. Thus, 'internal' imidazolidin-4-ones derived from dipeptidyl 8-aminoquinolines represent a new entry in antimalarial structure-activity relationships.
\end{abstract}

(c) 2008 Elsevier Ltd. All rights reserved.
Primaquine, $\mathbf{1}$, is the only currently available drug that is active against both the latent liver forms of the relapsing malaria caused by Plasmodium vivax and Plasmodium ovale and the gametocytes from all species of parasite causing human malaria. ${ }^{1}$ However, primaquine presents a short plasma half-life (ca. $6 \mathrm{~h}$ ), ${ }^{2}$ presumably due to its rapid oxidative deamination to carboxyprimaquine $\mathbf{2}^{3-5}$ Blood toxicity, in particular hemolysis secondary to the ability of primaquine to induce oxidation of oxyhemoglobin to methemoglobin, has also been a source of concern. ${ }^{6}$ Peptide and amino acid derivatives of primaquine have been prepared to reduce toxicity of the parent drug as well as to suppress the metabolic pathway leading to $\mathbf{2}^{7^{-10}}$ but many of these derivatives are rapidly hydrolyzed to primaquine by aminopeptidases and endopeptidases. ${ }^{8,10}$

Imidazolidin-4-one formation is often used to protect the N-terminal amino acid residue of peptides and peptidomimetics. ${ }^{11,12}$ Recently, we prepared imidazolidin-4-ones, 3, as potential peptidase-stable prodrugs of amino acid derivatives of primaquine. ${ }^{13-15}$ Compounds 3 displayed gametocytocidal activity against Plasmodium berghei comparable to that of primaquine, as well as activity against $P$. falciparum asexual stages, while presenting high stability in pH 7.4 buffer (half-lives for hydrolysis typically higher

\footnotetext{
* Corresponding author. Tel.: +351 220402563; fax: +351 220402659.

E-mail address: pgomes@fc.up.pt (P. Gomes).
}

than $12 \mathrm{~h}){ }^{14,16}$ We now set out to incorporate the imidazolidin-4one moiety into dipeptide derivatives of primaquine, for example, 5 (Scheme 1), both to (i) introduce a terminal basic amino group reported as relevant for activity, ${ }^{17}$ and (ii) effectively suppress hydrolysis of the imidazolidin-4-one due to acylation of the $N^{1}$ nitrogen atom. We herein report the synthesis and evaluation of the antiplasmodial activity of imidazolidin-4-ones 5 (Scheme 1).<smiles>[X]CCC(C)Nc1cc(OC)cc2cccnc12</smiles>

$$
\text { 1, } \mathrm{X}=\mathrm{CH}_{2} \mathrm{NH}_{2} \quad 2, \mathrm{X}=\mathrm{CO}_{2} \mathrm{H}
$$

Compounds 5 were prepared as depicted in Scheme 1. $\alpha$-Aminoacyl derivatives of primaquine, $\mathbf{4}$, were converted into the corresponding imidazolidin-4-ones 3 by refluxing with propanone, cyclopentanone, or cyclohexanone in $\mathrm{MeOH} .{ }^{18}$ Preliminary condensation of $\mathbf{3}$ with $\mathrm{N}$-Boc-protected amino acids (BocAAOH) using 


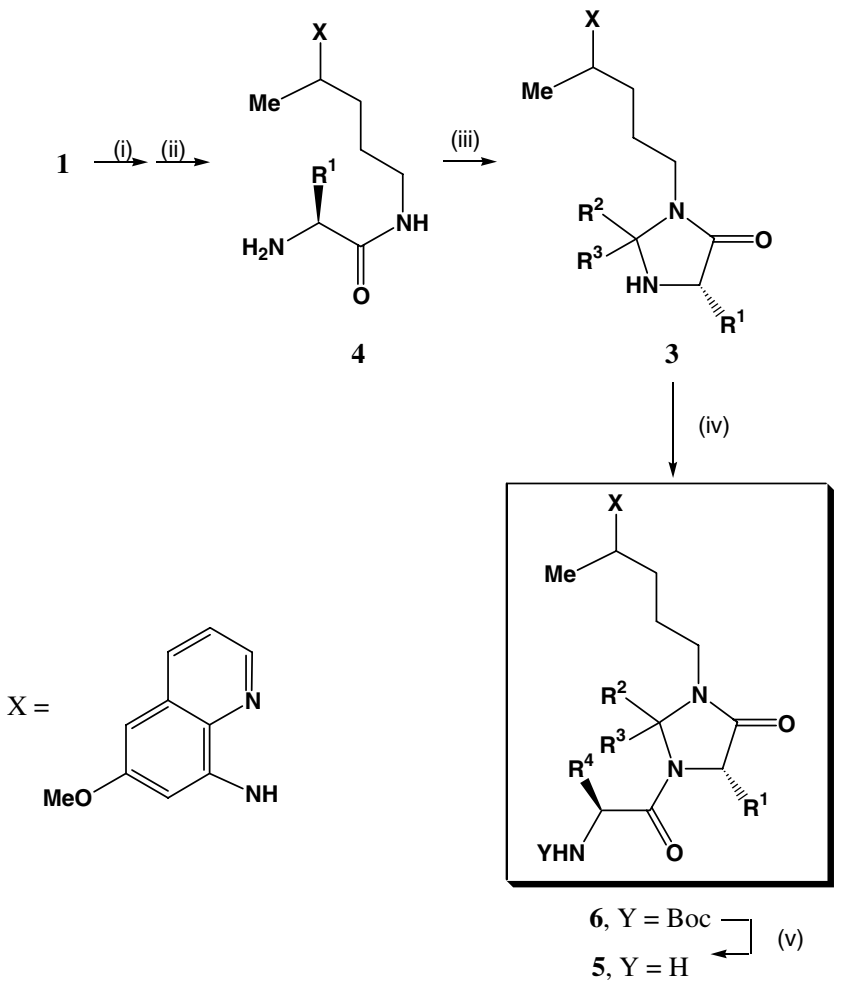

Scheme 1. Synthetic route to PQ-derived imidazolidin-4-ones 5. Reagents and conditions: (i) 1 equiv BocAAOH, 1.1 equiv DIPCDI, 1.1 equiv HOBt, 1 equiv TEA, $\mathrm{DCM}, 0{ }^{\circ} \mathrm{C} / \mathrm{rt}$; (ii) TFA, rt, $30 \%$ aq $\mathrm{Na}_{2} \mathrm{CO}_{3}$, extraction with $\mathrm{CHCl}_{3}$; (iii) $\mathrm{R}^{2}(\mathrm{C}=\mathrm{O}) \mathrm{R}^{3}, \mathrm{TEA}$, refluxing $\mathrm{MeOH}$; (iv) 5 equiv BocAAOH, 5 equiv DIPCDI/HOBt, 3 equiv TEA, DMF, $-10^{\circ} \mathrm{C} \rightarrow \mathrm{rt}, \mathrm{N}_{2}$; (v) TFA/DCM $30 \%$, rt, followed by $\mathrm{Na}_{2} \mathrm{CO}_{3}$ aq $30 \%$ and extraction with DCM.

DCCI as coupling agent failed to give compounds $\mathbf{6}$. Similar difficulties were reported for the solid-phase synthesis of Leu-Enkephalin peptidomimetics based on the imidazolidin-4-one scaffold, where resin-bound dipeptide imidazolidin-4-ones containing two methyl groups at C-2 failed to give the desired $N^{1}$-acylated products. ${ }^{19}$ Thus, we decided to optimize the coupling reaction of $\mathbf{3 a}\left(\mathrm{R}^{1}=\mathrm{H}\right.$, $\mathrm{R}^{2}=\mathrm{R}^{3}=\mathrm{Me}$ ) with BocGlyOH. Different cocktails of coupling reagents in DMF were used, of which the most efficient were DIPCDI and HOBt ( $87 \%$ yield of $\left.6 \mathbf{a} ; \mathrm{R}^{1}=\mathrm{R}^{4}=\mathrm{H}, \mathrm{R}^{2}=\mathrm{R}^{3}=\mathrm{Me}\right){ }^{20}$ The best coupling method (DIPCDI/HOBt) was then assayed in different solvents, with DMF remaining the best, followed by ACN (76\% yield) and DCM (34\%). Coupling did not take place in THF. These results suggest that the effectiveness of the acylation increases along with the solvent's dielectric constant. When 3a was reacted with bulkier BocAAOH (AA = Ala, Val, Leu, Phe, and Met) using DIPCDI/HOBt in DMF, the resulting compounds $\mathbf{6 b}-\mathbf{f}$ were obtained only in moderate yield (Scheme 1 and Table 1 ). In contrast, acylation of alaninebased imidazolidin-4-one $\mathbf{3 b} \quad\left(\mathrm{R}^{1}=\mathrm{R}^{2}=\mathrm{R}^{3}=\mathrm{Me}\right)$ proceeded successfully with BocGlyOH to give $\mathbf{6 g}$ in moderate yield. Further increase in the size of substituents at the imidazolidin-4-one $\mathrm{C}-5$ position failed to give the corresponding derivatives $\mathbf{6}$, with exception of $3 \mathbf{c}\left(\mathrm{R}^{1}=\mathrm{CH}_{2} \mathrm{CH}_{2} \mathrm{SMe}, \mathrm{R}^{2}=\mathrm{R}^{3}=\mathrm{Me}\right)$ that gave $\mathbf{6 h}$ in very poor yield $(1.6 \%)$ by reaction with BocGlyOH. Unfortunately, attempts to prepare the spiro counterparts of $\mathbf{6}$, starting from imidazolidin-4-ones 3 derived from cyclopentanone or cyclohexanone, were also unsuccessful. Removal of Boc from 6 using 30\% TFA in DCM gave compounds $\mathbf{5}$ almost quantitatively, ${ }^{21}$ with the exception of $\mathbf{6 h}$, which decomposed under these conditions.

The structure of imidazolidin-4-ones $\mathbf{5}$ and $\mathbf{6}$ follows from their spectroscopic data, which reveal the presence of two diastereomers resulting from using racemic primaquine as starting material. For example, the imidazolidin-4-one C-2 methyl proton signals of $\mathbf{6}, \mathbf{5 b}-\mathbf{g}$ appear as two sets of two singlets (1:1:1:1 integration). ${ }^{22}$ Similarly, the two methyl groups at C-2 appear as four signals in the ${ }^{13} \mathrm{C}$ NMR spectra (cf. Supporting Information). The ${ }^{1} \mathrm{H}$ NMR signal of the $\mathrm{C}-5 \mathrm{CH}_{2}$ of $\mathbf{6}, \mathbf{5 a}-\mathbf{f}$ indicates the diastereotopic nature of the two protons, which appear as an $\mathrm{AB}$ system at $\delta$ ca. $4 \mathrm{ppm}$, with ${ }^{2} J=14-16 \mathrm{~Hz}$. All attempts to separate the two diastereomers using column chromatography, flash chromatography, and preparative TLC were unsuccessful. Moreover, reverse-phase HPLC using Merck's RP-8 and RP-18 columns (both 125 and $250 \mathrm{~mm}$ ) consistently gave single peaks for each derivative $\mathbf{5 b}-\mathbf{g}$ (not shown), indicating that both diastereomers display similar properties, making their separation extremely difficult to achieve by standard methods. The same separation problem had already been observed for precursor compounds $\mathbf{3}$ and dipeptide derivatives of primaquine. ${ }^{10,13-16,18}$

Imidazolidin-4-ones $\mathbf{5 a - g}$ were evaluated against the chloroquine-resistant $P$. falciparum strain $\mathrm{W} 2$, and $\mathrm{IC}_{50}$ values obtained are given in Table 1 , together with those previously determined ${ }^{15}$ for the parent drug, $\mathbf{1}$, and also for precursors $\mathbf{3 a}$ and $\mathbf{3 b}$. $\mathrm{IC}_{50}$ values for 5 range from 5.5 to $12 \mu \mathrm{M}$, with one compound $(\mathbf{5 g})$ displaying activity close to that of primaquine, $\mathbf{1}(3.3 \mu \mathrm{M})$. Inspection of the data in Table 1 shows that antiplasmodial activity is slightly affected by the nature of substituents $\mathrm{R}^{4}$ in the N-terminal amino acid moiety. For example, the glycyl derivative $\mathbf{5 a}\left(\mathrm{R}^{1}=\mathrm{R}^{4}=\mathrm{H}\right)$ is equipotent with its leucyl counterpart $5 \mathbf{d}\left(\mathrm{R}^{1}=\mathrm{H}, \mathrm{R}^{4}={ }^{i} \mathrm{Bu}\right)$ and ca. two times more active than its methioninyl counterpart $\mathbf{5 f}$ $\left(\mathrm{R}^{1}=\mathrm{H}, \mathrm{R}^{4}=\mathrm{CH}_{2} \mathrm{CH}_{2} \mathrm{SMe}\right)$, thus suggesting that large hydrophobic

Table 1

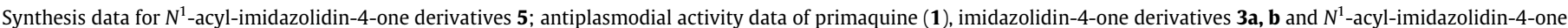
derivatives 5

\begin{tabular}{|c|c|c|c|c|c|}
\hline Compound & $\mathrm{R}^{1}$ & $\mathrm{R}^{2} / \mathrm{R}^{3}$ & $\mathrm{R}^{4}$ & Yield in $\%{ }^{\mathrm{a}}$ & P. falciparum W2 $\mathrm{IC}_{50}^{\mathrm{b}}(\mu \mathrm{M})$ \\
\hline 1 & - & - & - & - & $3.3^{c}$ \\
\hline $3 a$ & $\mathrm{H}$ & $\mathrm{Me} / \mathrm{Me}$ & - & - & $9.1^{\mathrm{c}}$ \\
\hline 3b & Me & $\mathrm{Me} / \mathrm{Me}$ & - & - & $>50^{c}$ \\
\hline $5 a$ & $\mathrm{H}$ & $\mathrm{Me} / \mathrm{Me}$ & $\mathrm{H}$ & (87) 86 & $6.7 \pm 0.2$ \\
\hline $5 \mathbf{b}$ & $\mathrm{H}$ & $\mathrm{Me} / \mathrm{Me}$ & $\mathrm{Me}$ & (71) 93 & $8.0 \pm 0.5$ \\
\hline $5 c$ & $\mathrm{H}$ & $\mathrm{Me} / \mathrm{Me}$ & ${ }^{i} \operatorname{Pr}$ & (69) 89 & $7.9 \pm 0.4$ \\
\hline $5 d$ & $\mathrm{H}$ & $\mathrm{Me} / \mathrm{Me}$ & ${ }^{i} \mathrm{Bu}$ & (37) 81 & $6.3 \pm 0.1$ \\
\hline $5 e$ & $\mathrm{H}$ & $\mathrm{Me} / \mathrm{Me}$ & Bzl & (69) 98 & $10 \pm 1$ \\
\hline $5 f$ & $\mathrm{H}$ & $\mathrm{Me} / \mathrm{Me}$ & $\left(\mathrm{CH}_{2}\right)_{2} \mathrm{SMe}$ & (68) 91 & $12 \pm 1$ \\
\hline $5 g$ & $\mathrm{Me}$ & $\mathrm{Me} / \mathrm{Me}$ & $\mathrm{H}$ & (58) 84 & $5.5 \pm 0.2$ \\
\hline $5 h$ & $\left(\mathrm{CH}_{2}\right)_{2} \mathrm{SMe}$ & $\mathrm{Me} / \mathrm{Me}$ & $\mathrm{H}$ & $\left(1.6^{\mathrm{d}}\right)-$ & - \\
\hline
\end{tabular}

a Yields for Boc removal to obtain 5; in parentheses are the yields for the coupling reaction to obtain $\mathbf{6}$.

b Assays were performed as described in Ref. 15.

c From Ref. 15.

d Compound $\mathbf{6 h}$ decomposed in the acidolytic removal of Boc. 
amino acids at the N-terminus of the peptide backbone are somewhat detrimental for antiplasmodial activity. Considering the effect of $\mathrm{R}^{1}$ substituents at the $\mathrm{C}-5$ position of imidazolidin-4-ones 5 on antiplasmodial activity, the results also suggest that $R^{1}$ does not have a marked influence on activity against $P$. falciparum: changing $\mathrm{H}$ for Me at $\mathrm{R}^{1}$ (i.e., $\mathbf{5 a}$ vs $\mathbf{5 g}$ ) leads only to a marginal increase in activity. Although these SARs are based on diastereomeric mixtures, it should be noted that the enantiomers of primaquine are equipotent antimalarials. ${ }^{23}$

Compounds $\mathbf{5}$ are generally more active than their $\mathrm{N}$-terminal imidazolidin-4-one precursors 3 , particularly when $R^{1}=M e$, as shown by at least 10 -fold difference in $\mathrm{IC}_{50}$ values against $P$. falciparum between the alanine-based imidazolidin-4-one $\mathbf{3 b}$ and its $N^{1}$-glycyl derivative $\mathbf{5 g}$. This result is consistent with the previously mentioned relevance of a free primary amino group for antiplasmodial activity. ${ }^{17}$

The potential of compounds $\mathbf{5 a} \mathbf{a}, \mathbf{b}, \mathbf{e}$ to prevent the transmission of malaria was studied using a model consisting of BalbC mice infected with $P$. berghei and Anopheles stephensi mosquitoes and compared to that of primaquine. ${ }^{14,24}$ The antimalarial activity was assessed based on the percentage of mosquitoes with oocysts and the mean number of oocysts per infected mosquito (Table 2). Although this model cannot specifically attribute the drug effect to either gametocytocidal or sporontocidal activity, it can clearly show if a compound is effective at interrupting the transmission of the infection to mosquitoes by interference with the cycle in these insects. ${ }^{25,26}$ Compounds 5a, e significantly reduced $(P<0.05)$ the sporogonic development of $P$. berghei at 10 and $50 \mu \mathrm{mol} / \mathrm{kg}$ when compared with the control, though they did not completely inhibit the production of oocysts at $50 \mu \mathrm{mol} / \mathrm{kg}$. Compound 5b was inactive at $10 \mu \mathrm{mol} / \mathrm{kg}$.

The decomposition of compounds $\mathbf{5}$ was studied in non-enzymatic and enzymatic conditions using HPLC. No traces of products resulting from either imidazolidin-4-one ring-opening (i.e., dipeptide derivatives of primaquine) or N-terminal amino acid hydrolysis (i.e., compounds 3 ) were detected when incubated in $\mathrm{pH} 7.4$ buffer and $80 \%$ human plasma at $37{ }^{\circ} \mathrm{C}$. This result confirms our initial prediction, that is, $N^{1}$-acyl imidazolidin-4-ones have negligible susceptibility to hydrolysis.

In conclusion, the synthesis of imidazolidin-4-one derivatives of primaquine, $\mathbf{5}$, was attained by solution phase acylation of imidazolidin-4-one precursors 3 with Boc-protected amino acids. Compounds 5 exhibit moderate activity against a chloroquineresistant strain of $P$. falciparum and inhibit the transmission of the infection to mosquitoes as efficiently as primaquine. Useful information concerning the effect of $\mathrm{R}^{1}$ and $\mathrm{R}^{4}$ on the bioactivity

Table 2

Effect of compounds $\mathbf{5 a}, \mathbf{5 b}$, and $\mathbf{5 e}$, and primaquine, 1, on the sporogonic development of Plasmodium berghei ANKA in Anopheles stephensi mosquitoes

\begin{tabular}{llll}
\hline Compound & Dose $/ \mu \mathrm{mol} \mathrm{kg}^{-1}$ & \% Infected mosquitoes & \\
& & $\begin{array}{l}\text { Mean no. of oocysts/ } \\
\text { mosquito }\left( \pm \mathrm{SM}^{\mathrm{b}}\right)\end{array}$ \\
\hline $\mathbf{1}$ & 0 & 65.4 & $16.3 \pm 3.85$ \\
& 10 & 41.7 & $2.00 \pm 1.05$ \\
& 50 & 42.9 & $0.95 \pm 0.35$ \\
$\mathbf{5 a}$ & 0 & 66.1 & $9.10 \pm 1.45$ \\
& 10 & 42.0 & $1.08 \pm 0.23$ \\
& 50 & 40.5 & $0.79 \pm 0.27$ \\
$\mathbf{5 b}$ & 0 & 66.1 & $9.10 \pm 1.45$ \\
& 10 & 67.9 & $9.71 \pm 2.49$ \\
& 50 & 40.1 & $1.34 \pm 0.31$ \\
$\mathbf{5 e}$ & 0 & 65.4 & $16.3 \pm 3.85$ \\
& 10 & 43.8 & $3.69 \pm 1.17$ \\
& 50 & 40.0 & $2.20 \pm 0.77$ \\
\hline
\end{tabular}

a Counting of oocysts was carried out at day 10 post-feed.

b Mean standard error. of $\mathbf{5}$ could be established, despite the obvious limitations imposed by the relatively small number of compounds included in this preliminary study. The high aqueous stability displayed by $\mathbf{5}$ suggests that incorporation of an imidazolidin-4-one moiety into the C-terminus of a dipeptide derivative of primaquine might be a useful approach to obtain chemically and enzymatically stable peptidomimetic derivatives of 8-aminoquinoline antimalarials. Recent reports indicate that adequate substitution at the $C-2, C-4$, and $C-5$ positions of the quinoline moiety can lead to potent 8-aminoquinoline blood-schizontocidal antimalarials devoid of significant blood toxicity. ${ }^{27}$ Therefore, combination of the imidazolidin-4one scaffold with the appropriately substituted quinoline moiety deserves further attention.

\section{Acknowledgments}

R.M. and P.G. were supported by Grant POCTI/FCB/39218/2001 from Foundation for Science and Technology (FCT, Portugal). N.V. thanks FCT for Ph.D. Grant SFRH/BD/17754/2004. P.J.R. was supported by grants from the National Institutes of Health and Medicines for Malaria Venture.

\section{Supplementary data}

Supplementary data associated with this article can be found, in the online version, at doi:10.1016/j.bmcl.2008.05.076.

\section{References and notes}

1. Brueckner, R. P.; Ohrt, C.; Baird, J. K.; Milhous, W. K. 8-Aminoquinolines. In Antimalarial Chemotherapy; Rosenthal, P. J., Ed.; Humana Press: Totowa, 2001; p 123.

2. Mihaly, G. W.; Ward, S. A.; Edwards, G.; Orme, M. L. E.; Breckenridge, A. M. Br. J. Clin. Pharmacol. 1984, 17, 441.

3. Baker, J. K.; Bedford, J. A.; Clark, A. M.; McChesney, J. D. Pharm. Res. 1984, 1, 98

4. Baker, J. K.; Yarber, R. H.; Nanayakkara, N. P. D.; McChesney, J. D.; Homo, F.; Landau, I. Pharm. Res. 1990, 7, 91

5. Constantino, L.; Paixão, P.; Moreira, R.; Portela, M. J.; Rosário, V. E.; J. Iley J. Exp Toxicol. Pathol. 1999, 51, 299.

6. Umbreit, J. Am. J. Hematol. 2007, 82, 134.

7. Philip, A.; Kepler, J. A.; Johnson, B. H.; Carroll, F. Y. J. Med. Chem. 1988, 31, 870

8. Borissova, R.; Stjarnkvist, P.; Karlsson, M. O.; Sjoholm, I. J. Pharm. Sci. 1995, 84, 256

9. Chung, M. C.; Gonçalves, M. F.; Colli, W.; Ferreira, E. I.; Miranda, M. T. M. J. Pharm. Sci. 1997, 86, 1127.

10. Portela, M. J.; Moreira, R.; Valente, E.; Constantino, L.; Iley, J.; Pinto, J.; Rosa, R. Cravo, P.; Rosário, V. E. Pharm. Res. 1999, 16, 949.

11. Rasmussen, G. J.; Bundgaard, H. Int. J. Pharm. 1991, 71, 45.

12. Bak, A.; Fich, M.; Larsen, B. D.; Frokjaer, S.; Friis, G. J. Eur. J. Pharm. Sci. 1999, 7, 317.

13. Gomes, P.; Araújo, M. J.; Rodrigues, M.; Vale, N.; Azevedo, Z.; Iley, J.; Chambel, P.; Morais, J.; Moreira, R. Tetrahedron 2004, 60, 5551.

14. Araújo, M. J.; Bom, J.; Capela, R.; Casimiro, C.; Chambel, P.; Gomes, P.; Iley, J.; Lopes, F.; Morais, J.; Moreira, R.; Oliveira, E.; Rosário, V.; Vale, N. J. Med. Chem. 2005, 48,888 .

15. Vale, N.; Collins, M. S.; Gut, J.; Ferraz, R.; Rosenthal, P. J.; Cushion, M. T.; Moreira, R.; Gomes, P. Bioorg. Med. Chem. Lett. 2008, 18, 485.

16. Chambel, P.; Capela, R.; Lopes, F.; Iley, J.; Morais, J.; Gouveia, L.; Gomes, J. R. B.; Gomes, P.; Moreira, R. Tetrahedron 2006, 62, 9883.

17. Nodiff, E. A.; Chatterjee, S.; Musallam, H. A. Prog. Med. Chem. 1991, $28,1$.

18. Ferraz, R.; Gomes, J. R. B.; Oliveira, E.; Moreira, R.; Gomes, P. J. Org. Chem. 2007 72,4189

19. Rinnová, M.; Nefzi, A.; Houghten, R. A. Tetrahedron Lett. 2002, 43, 2343.

20. Synthesis of compound 6a was carried out as follows: compound $\mathbf{3 a}(1 \mathrm{mmol})$ was suspended in solvent $(20 \mathrm{~mL}), \mathrm{TEA}$ ( 3 equiv) and the mixture was stirred at $-10^{\circ} \mathrm{C}$ for $20 \mathrm{~min}$, under inert atmosphere. After addition of BocGlyOH (5 equiv) plus DIPCDI (5 equiv), the mixture was kept at $-10^{\circ} \mathrm{C}$ for further $4 \mathrm{~h}$ under stirring. The temperature was then increased to $10^{\circ} \mathrm{C}$ and thus maintained till the end of reaction ( $24 \mathrm{~h}$ by TLC). The solid was removed by suction filtration, the liquid phase was evaporated at $90{ }^{\circ} \mathrm{C}$ in vacuum to dryness and the resulting residue was dissolved in $40 \mathrm{~mL}$ of DCM. This solution was washed three times with $15 \mathrm{~mL}$ portions of $10 \%$ aq $\mathrm{NaHCO}_{3}$ and the organic layer dried over anhydrous $\mathrm{MgSO}_{4}$ and evaporated to dryness. The residue was submitted to column chromatography on silica using DCM/ acetone. The product was isolated as yellow-orange oil and identified as $6 \mathbf{a} ; \delta_{\mathrm{H}}$ $8.51(1 \mathrm{H}$, dd, $J=4.20,1.38) ; 7.92(1 \mathrm{H}$, dd, $J=8.26,1.42 \mathrm{~Hz}) ; 7.30(1 \mathrm{H}$, dd 
$J=8.28,4.20) ; 6.34$ (1H, d, $J=2.45) ; 6.28$ (1H, d, $J=2.43) ; 6.01$ (1H, d, $J=8.22)$; $5.35(1 \mathrm{H}, \mathrm{br} \mathrm{s}) ; 3.95(2 \mathrm{H}, \mathrm{s}) ; 3.89(3 \mathrm{H}, \mathrm{s}) ; 3.81(2 \mathrm{H}, \mathrm{d}, J=4.31) ; 3.69-3.63(1 \mathrm{H}$, $\mathrm{m}) ; 3.30-3.18(2 \mathrm{H}, \mathrm{m}) ; 1.84-1.72(4 \mathrm{H}, \mathrm{m}) ; 1.60(4)$ and $1.59(9)(6 \mathrm{H}, \mathrm{s}+\mathrm{s}) ; 1.44$ $(9 \mathrm{H}, \mathrm{s}) ; 1.31$ (3H, d, $J=6.30) . \delta_{\mathrm{c}}, 166.03 ; 165.36 ; 159.50 ; 155.84 ; 145.03$; 144.43; 135.42; 134.89; 129.99; 121.99; 96.90; 91.88; 80.91; 79.99; 55.33; $47.92 ; 47.16 ; 43.80 ; 39.91 ; 34.13 ; 28.42 ; 25.84 ; 24.60 ; 24.52 ; 20.81 . \mathrm{m} / \mathrm{z}$ $\left(\mathrm{M}+\mathrm{H}^{+}\right)=514.21($ calcd, 514.30). The different coupling methods assayed for the preparation of compounds $\mathbf{6}$ and the corresponding yields are in the Supporting Information, together with spectroscopic data.

21. Acidolytic removal of Boc: compounds $\mathbf{6}$ were dissolved in TFA at $30 \%$ in DCM and the reaction was allowed to proceed for $2 \mathrm{~h}$ at room temperature. Excess TFA was neutralized by dropwise addition of $30 \% \mathrm{aq} \mathrm{Na}_{2} \mathrm{CO}_{3}$ until $\mathrm{pH} 10$; the supernatant oily layer formed was extracted six times with $10 \mathrm{~mL}$ portions of chloroform and the organic layers pooled, dried over anhydrous $\mathrm{MgSO}_{4}$ and evaporated to dryness. Chromatographically homogeneous yellow-orange oils were obtained and identified as the target structures 5 (cf. Supporting Information).

22. See Supporting Information for detailed spectroscopic data.

23. Brossi, A.; Millet, P.; Landau, I.; Bembenek, M. E.; Abell, C. W. FEBS Lett. 1987, 214, 291.

24. Coleman, R. E.; Vaughan, J. A.; Hayes, D. O.; Hollingdale, M. R.; Do Rosário, V. E. Acta Leiden. 1988, 57, 61.

25. Coleman, R. E.; Clavin, A. M.; Milhous, W. K. Am. J. Trop. Med. Hyg. 1992, 46, 169

26. Coleman, R. E.; Nath, A. K.; Schneider, I.; Song, G.-H.; Klein, T. A.; Milhous, W. K. Am. J. Trop. Med. Hyg. 1994, 50, 646

27. Vangapandu, S.; Sachdeva, S.; Jain, R.; Jain, M.; Singh, S.; Singh, P. P.; Kaul, C. L.; Jain, R. Bioorg. Med. Chem. 2004, 12, 239. 